Though further studies are necessary to determine the optimum dosage regimen to maximize the diagnostic efficiency of the test, it would appear that the use of the thyroid functional index suggested would minimize the possible adverse effects of $T_{3}$ administration in the presence of thyrotoxicosis.

We would like to thank our colleagues who allowed us to carry out studies on them and the members of the consultant staff of the Middlesex Hospital who referred patients to us for investigation and so enabled this work to be carried out.
REFERENCES

Ekins, R. P., Williams, E. S., and Ellis, S. (1969). Clinical Biochemistry, 2, 252 .

Fisher, D. A., and Oddie, T. H. (1964). Fournal of Clinical Endocrinology and Metabolism, 24, 733.

Greer, M. A., and Smith, G. E. (1954). Fournal of Clinical Endocrinology and Metabolism, 14, 1374 .

Sönksen, P. H., Ekins, R. P., Stevens, H. G., Williams, E. S., and Nabarro, J. D. N. (1968). Lancet, 2, 425.

Werner, S. C., and Spooner, M. (1955). Bulletin of the New York Academy of Medicine, 31, 137

Williams, E. S., Ekins, R. P., and Ellis, S. M. (1969). British Medical fournal, 4, 16.

\title{
Levamisole in the Treatment of Ascariasis in Children
}

\author{
N. D. W. LIONEL,* M.B., B.S., M.R.C.P.ED. ; E. H. MIRANDO,† F.R.C.P.ED, D.C.H. \\ JASMINE C. NANAYAKKARA, $\ddagger$ M.B., B.S., D.C.H. ; PRIYANI E. SOYSA,§ M.D., M.R.C.P.ED., D.C.H.
}

\begin{abstract}
Cummary : Levamisole (the laevorotatory isomer of tetramisole) is a new synthetic anthelmintic. A cure rate of $91 \%$ was obtained in a series of 111 ascariasisinfected children treated with a single oral dose of the drug. The failures, who were treated with the drug a second time one week later, were all cured. In a comparative study of levamisole and piperazine citrate in a series of 100 children with ascariasis a cure rate of $92 \%$ and $90 \%$ was obtained with a single dose of levamisole and piperazine respectively, indicating equal efficacy. Levamisole is better tolerated than piperazine citrate and is virtually free of toxic effects.
\end{abstract}

\section{Introduction}

Tetramisole is a synthetic compound which has been found to possess anthelmintic properties. Chemically it is the hydrochloride of 2,3,5,6-tetrahydro-6-phenylimidazo $(2,1-b)$ thiazole. The racemic mixture of tetramisole has been found to be effective at low dose levels against a variety of nematodes.

Clinical trials carried out in South America (Mesquita and Daher, 1966 ; Nascimento Filha et al., 1966) and South Africa (Seftel and Heinz, 1968) showed that it is highly effective and safe in the treatment of ascariasis in man.

Further studies in rats, mice, sheep, and cattle have shown that levamisole, the laevo-isomer of tetramisole, is about twice as active as the racemic mixture, and, depending on the parasite, several times more active than the dextro-isomer (Rohrbacher et al., 1967 ; Bullock et al., 1968. In rats and mice the $\mathrm{LD}_{50}$ values for the two isomers and for racemic tetramisole proved almost identical (Raeymaekers et al., 1967). These findings indicated that levamisole would be as effective as the racemic mixture at a lower dosage, and that the safety margin could correspondingly be increased.

It was therefore decided to conduct a clinical trial to assess the therapeutic and toxic effects of levamisole in the treatment of ascariasis in children.

\section{Patients and Methods}

The trial was carried out in two stages. The first stage was to determine the efficacy and safety of levamisole in the treat-

\footnotetext{
- Lecturer, Department of Pharmacology, University of Ceylon, Colombo.

Physician, Lady Ridgeway Hospital, Colombo.

Pecturer, Department of Paedintrics, University of Ceylon, Colombo.

\$ Professor of Paediatrics, University of Ceylon, Colombo.
}

ment of ascariasis in children, and the second stage was to compare its effects with those of piperazine, at present the drug of choice in treating ascariasis.

Children whose stools showed ascaris ova on faecal smear examination were selected for the trial from those admitted to two wards of the Lady Ridgeway Hospital, Colombo. The stools were examined with the faecal smear technique (Beaver, 1961), a recognized method of carrying out ascaris ova counts (W.H.O., 1964).

In the first stage of the trial the effects of levamisole were determined in 111 patients, many of whom had symptoms suggestive of ascariasis, such as vomiting, diarrhoea, and abdominal pain. Four of them were drowsy and dehydrated, 22 showed evidence of malnutrition, and 12 were severely anaemic with haemoglobin levels below $7 \cdot 4$ g. $/ 100 \mathrm{ml}$. Eightyone were between 2 and 9 years of age, 13 less than 2 years, and 17 over 9 years. Liver function tests were carried out before and after treatment on 14 patients, and haemoglobin estimations on 20 patients selected randomly, to determine possible hepatic and haemopoietic toxicity.

In the second stage of the trial 100 children were randomly allocated to two groups, one group being treated with levamisole and the other with piperazine. At the end of the trial there were 50 patients in each group. Table I compares the two treatment groups with regard to sex and age. Table II shows the similarity of the presenting symptoms in the patients in the two groups before treatment.

TABLE I.-Comparability of Treatment Groups with Regard to Sex and

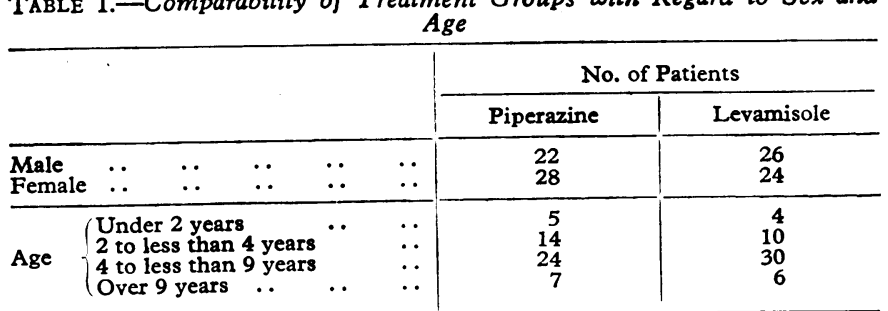

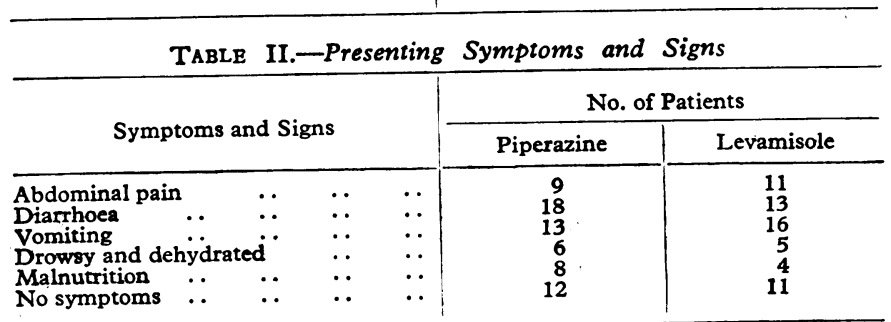


Levamisole was administered in the form of red sugar-coated tablets of $20 \mathrm{mg}$. each. The dose was calculated according to age. Children under 3 years of age received $40 \mathrm{mg}$., those over 3 years but less than 9 years received $60 \mathrm{mg}$., and those over 9 years received $80 \mathrm{mg}$.

Piperazine was given in the form of piperazine citrate syrup (Antepar). The doses used were 4 teaspoonfuls for children weighing less than $20 \mathrm{~kg}$. and 8 teaspoonfuls for children weighing over $20 \mathrm{~kg}$. Each teaspoonful contained the equivalent of about $500 \mathrm{mg}$. of piperazine hexahydrate.

Both drugs were administered, as a single dose after food, by a nurse who ensured that the drugs were swallowed by the children. There was no restriction of food and no purgation after treatment. No difficulty was experienced in administering the levamisole tablets, as they were small, were brightly coloured, and only a few had to be taken.

\section{Assessment of Treatment}

The effect of treatment was assessed from examination of the stools for ascaris ova after at least one week following drug administration. Two smears were examined from the posttreatment sample of stools with the faecal smear technique described by Beaver (1961). If negative, the specimens were examined by the brine flotation method (W.H.O., 1967). Patients were considered cured only if both methods did not reveal the presence of any ascaris ova in the specimens examined. All the stools were examined by one laboratory technician, who was unaware of the treatment given.

All the patients were carefully observed for adverse effects for at least 24 hours after administration of the drug. Many of the patients remained in the ward until the post-treatment stools were examined. Others remained in the wards for at least two days and then returned one week after treatment for collection of post-treatment specimens of stools.

\section{Results}

There were 10 failures among the 111 patients treated with levamisole, giving a single dose cure rate of $91 \%$. The failures were all cured when treated a second time a week later. The worms were usually expelled within 24 hours of treatment, but in a few instances some were passed even on the second day after treatment.

In the comparative trial 46 out of 50 patients treated with levamisole and 45 out of 50 treated with piperazine were completely cured, giving a cure rate of $92 \%$ and $90 \%$ respectively. This difference is not statistically significant.

Adverse Effects.-Levamisole was well tolerated, for no nausea and vomiting was observed in any of the 161 children treated with the drug. Vomiting occurred in 3 out of the 50 patients treated with piperazine, none of whom had symptoms of vomiting before treatment. No other adverse effects were seen with piperazine. In the first part of the trial with levamisole a transient rise of temperature was noted in one patient three hours after its administration. Another patient had loose motions 24 hours after treatment. Generalized convulsions were reported about 10 hours after treatment in a third patient who had no previous history of fits ; they subsided spontaneously. In all these instances there was no definite evidence of a causal relationship. Levamisole had no adverse effects on the haemoglobin level and liver function.

\section{Discussion}

None of the drugs available at present for the treatment of ascariasis is $100 \%$ effective in eradicating the infection. A single dose of piperazine produces a cure rate of $80-90 \%$, and while serious toxic effects are rare nausea and vomiting are not uncommon.

Recently it has been shown that the racemic mixture of tetramisole is also effective in eradicating ascaris infection in about $80-90 \%$ of cases, and in one comparative trial it was found to be marginally more effective than piperazine (Seftel and Heinz, 1968). While this drug is reported to be effective and to be free of serious hepatic, renal, or haemopoietic toxicity, adverse effects such as nausea, vomiting, abdominal pain, and vertigo have sometimes been encountered. The subsequent discovery that the anthelmintic activity is confined to the laevorotatory isomer while both isomers had the same degree of toxicity suggested that the laevorotatory isomer would be effective at lower dose levels than the racemic mixture, with possible reduction in the incidence of adverse effects.

Our studies with levamisole indicate that it produces a single-dose cure rate of $91-92 \%$ in children with ascariasis. The failures were all cured when treated a second time. When levamisole and piperazine were compared they were found to be equally effective. Experimental evidence indicates that levamisole acts by paralysing ascaris muscle. This effect appears to be related to inhibition of succinic dehydrogenase activity in ascaris muscle which blocks the reduction of fumarate to succinate, an important step in the anaerobic metabolism of ascaris muscle (Van den Bossche and Janssen, 1967).

Levamisole was well tolerated and there was no evidence of serious toxicity, while piperazine caused vomiting in $6 \%$ of cases without any other evidence of toxicity.

Our studies indicate that levamisole is highly effective in the treatment of ascariasis and that it is comparable to piperazine in efficacy. It is better tolerated than piperazine and is therefore more acceptable. There was no difficulty in administering levamisole to children, and the cost of treatment is comparable to that of piperazine.

We wish to thank Mr. A. A. Amarasiri, of the Department of Pharmacology, University of Ceylon, Colombo, for technical assistance in examining the stools; all members of the medical and nursing staff who were associated with this work for their help; and $\mathrm{Dr}$. H. A. Johnston, of I.C.I. Ltd., for his invaluable advice and assistance in obtaining, supplies of levamisole (Ketrax).

\section{REFBRENCES}

Beaver, P. C. (1961). World Health Organization Public Health Papers, No. 10, p. 39.

Bullock, M. W., Hand, J. J., and Waletzky, E. (1968). fournal of Medicinal Chemistry, 11, 169.

Mesquita, P. M., and Daher, H. R. (1966). Hospital (Rio de faneiro), 69, 1279.

Nascimento Filha, O. B. do, Halsman, M., Oria, H., and Campos, J. V. M. (1966). Revista do Instituto de Medicina Tropical de São Paulo, 8, 143 .

Raeymaekers, A. H. M., Roevens, L. F. C., and Janssen, P. A. (1967). Tetrahedron Letters, 16, 1467.

Rohrbacher, G. H., Emro, J., and Waletzky, E. (1967). Paper delivered to the American Society of Parasitologists.

Seftel, H. C., and Heinz, H. J. (1968). British Medical fournal, 4, 93. Van den Bossche, H., and Janssen, P. A. (1967). Life Sciences, 6, 1781. World Health Organization (1964). Tecknical Report Series, No. 277.

World Health Organization (1967). Technical Report Series, No. 379, p. 47. 